\title{
Induced Plasticity of a Brittle (La, Ce)-Based Bulk Metallic Glass by Surface Corrosion
}

\author{
Ji-Juan Liu ${ }^{1} \cdot{\operatorname{Ran~} \mathrm{Li}^{1} \cdot \text { Lian-Xiang Fang }}^{1} \cdot \mathrm{Ju} \mathrm{Wang}^{1} \cdot$ Tao Zhang $^{1}$
}

Received: 2 August 2015/Revised: 1 October 2015/Published online: 18 January 2016

(C) The Chinese Society for Metals and Springer-Verlag Berlin Heidelberg 2016

\begin{abstract}
Unexpected facture without any room-temperature plasticity severely limits potential structural applications of bulk metallic glasses (BMGs), especially La-, Mg- and Fe-based ones. In this study, a simple free corrosion method was provided to improve the plasticity of a brittle ( $\mathrm{La}, \mathrm{Ce}$ )-based $\mathrm{BMG}$ by the introduction of high-density corrosion defects on the surface. The influences of immersing time in $0.1 \mathrm{~mol} / \mathrm{L} \mathrm{H}_{2} \mathrm{SO}_{4}$ aqueous solution on the surface morphology and mechanical properties of the BMG were evaluated. With increasing immersing time from 5 to $30 \mathrm{~min}$, the degree of surface corrosion increased obviously, and the distribution of corrosion defects became more homogenous. In the samples, the yielding phenomenon and certain plasticity appeared up to $0.3 \%$ after the surface treatment. The yielding and plasticity can be attributed to easier nucleation of shear bands on the defect surface rather than on the glabrous surface. The results provided a novel method to improve the plasticity of BMGs.
\end{abstract}

\section{KEY WORDS: Metallic glasses; Corrosion plastic deformation mechanism; Rapid solidification;} Microstructure

\section{Introduction}

Bulk metallic glasses (BMGs) with high specific strength, high hardness, large elastic limit and other novel chemical and physical properties are regarded as one of the most attractive advanced structural materials in engineering fields [1-6]. However, unpredictable fracture behaviors of these materials, especially La-, Mg- and Fe-based BMGs with zero plasticity, have strictly confined their possible applications as structural materials [2, 4, 7-9]. Shear bands play a key role in yielding and plasticity of all BMGs during deformation process at room temperature [7]. How

Available online at http://link.springer.com/journal/40195

\section{Ran Li}

liran@buaa.edu.cn

1 Key Laboratory of Aerospace Materials and Performance (Ministry of Education), School of Materials Science and Engineering, Beihang University, Beijing 100191, China to control (or "design") the formation and evolution of shear bands is a final purpose to overcome the obstacle of the catastrophic failure of BMGs.

Various approaches, such as adjusting alloy composition, controlling sample size and shape, synthesizing glassy matrix composites with in situ or ex situ second phase and performing mechanical or surface treatments, have been successfully provided to enhance plasticity of BMGs $[4,7$, 10]. Among these methods, surface treatments, like shot peening [11], surface coating [12, 13], pattern imprinting $[14,15]$ and laser treatment $[16,17]$, can be regarded as one of the most convenient ways to improve room-temperature macroscopic plasticity of BMGs. Zhang et al. [11] reported that the compressive plasticity of shot-peened $\mathrm{Zr}$ based BMG samples can be increased near three times compared with that of as-cast ones. The roughness (pits, flaws, micro-cracks, etc.) and residual stress on the sample surface caused by shot-peening can promote the nucleation of shear bands and hinder their propagation, which are responsible for the improvement in plasticity. Scudino 
et al. [14] indicated that a Zr-based BMG with intrinsic tensile brittleness can be induced to show $\sim 0.9 \%$ tensile plasticity by imprinting with designed patterns (regularly arrayed troughs in the size of several hundred micrometers) on the sample surface. The stress fields caused by the regular surface construction can effectively limit the catastrophical propagation of shear bands. Therefore, surface modification with a certain proper roughness could drastically increase the plasticity of BMGs.

In light of the inspiration of the plastic improvement in BMGs by surface modification, we adopted a chemical corrosion method to induce corrosion defects on the surface of a brittle $\left(\mathrm{La}_{0.5} \mathrm{Ce}_{0.5}\right)_{65} \mathrm{Al}_{10} \mathrm{Cu}_{25} \mathrm{BMG}$. The influences of etching time on the evolution of surface morphology and the related compressive mechanical properties of the samples were investigated. The results might provide a novel way to improve the plasticity of BMGs.

\section{Experimental}

Ingots with the nominal chemical composition of $\left(\mathrm{La}_{0.5}\right.$ $\left.\mathrm{Ce}_{0.5}\right)_{65} \mathrm{Al}_{10} \mathrm{Cu}_{25}$ were prepared by arc melting the mixtures of pure $\mathrm{La}(99.9 \%), \mathrm{Ce}(99.99 \%), \mathrm{Al}(99.99 \%)$ and $\mathrm{Cu}(99.99 \%)$ in a highly purified argon atmosphere. Cylindrical glassy samples of $2 \mathrm{~mm}$ in diameter were prepared by injection casting into a copper mold in an argon atmosphere. The critical diameter of glass formation for the $\left(\mathrm{La}_{0.5} \mathrm{Ce}_{0.5}\right)_{65} \mathrm{Al}_{10} \mathrm{Cu}_{25}$ alloy has been reported up to $8 \mathrm{~mm}$, which can insure the fabrication of the fully amorphous samples [18, 19].

Surface corrosion of the glassy rods was performed in a $0.1 \mathrm{~mol} / \mathrm{L} \mathrm{H}_{2} \mathrm{SO}_{4}$ aqueous solution at $298 \mathrm{~K}$ under free corrosion conditions. Different immersing time of 5, 20 and $30 \mathrm{~min}$, respectively, was adopted to evaluate possible influences on surface microstructure, corrosion degree and the related mechanical properties of the specimens. The corroded samples were rinsed in distilled water and dehydrated in alcohol and then kept in the vacuum chamber until following characterizations. Phase structure of the ascast and etched rods samples was determined using a Bruker AXS D8 X-ray diffractometer (XRD) with $\mathrm{Cu} K_{\alpha}$ radiation. The as-cast and corroded rods with an aspect ratio of 2:1 were measured under compressive conditions using a universal testing machine (Instron 5565) at a strain rate of $1 \times 10^{-4} \mathrm{~s}^{-1}$ at room temperature. Surface morphologies of the as-cast, corroded and failed samples were observed using a JEOL JSM 6010LA electron microscope (SEM) coupled with an energy-dispersive X-ray analyzer (EDX). Quantitative microscopy [20] was employed by SEM image analysis to determine two parameters, i.e., the corrosion degree, which equals to the ratio of the linear size of corroded region with obvious corrosion defects (pits) to total line length in the chosen SEM images, and the density of shear bands, which is the ratio of the length of shear bands to entire surface area in the chosen SEM images. For each sample, at least five continuous SEM images at the same magnification and in the comparable region of the samples were analyzed, and the statistic average values were adopted.

\section{Results and Discussion}

Figure 1 shows the XRD patterns of the as-cast sample of $\left(\mathrm{La}_{0.5} \mathrm{Ce}_{0.5}\right)_{65} \mathrm{Al}_{10} \mathrm{Cu}_{25}$ and the corroded ones at $298 \mathrm{~K}$ in $0.1 \mathrm{~mol} / \mathrm{L} \mathrm{H}_{2} \mathrm{SO}_{4}$ aqueous solution for different immersing time of 5, 20 and $30 \mathrm{~min}$, respectively. The as-cast rods exhibit a broad halo without any sharp crystalline peak, characteristic of fully amorphous structure under a sensitivity of XRD. Insignificant difference in the XRD patterns between the corroded samples for $5 \mathrm{~min}$ and the as-cast ones can be observed. The amount of corrosion products on the surface of the corroded samples for the relatively short time might be insufficient for the sensitivity of XRD, which is responsible for the absence of any crystalline phase. Sharp crystalline diffraction peaks, identified as $\mathrm{Cu}$ and $\mathrm{CeO}_{2}$, are detected for the samples corroded for longer time of 20 and $30 \mathrm{~min}$. Due to high chemical activity of rare earth ( $\mathrm{La}$ and $\mathrm{Ce}$ ) and $\mathrm{Al}$ atoms in $\mathrm{H}_{2} \mathrm{SO}_{4}$ aqueous solution, these less-noble atoms are continuously fast dissolved into the solution, while the noble atoms of $\mathrm{Cu}$ are enriched on the surface. The phenomenon, called as dealloying, has been reported in other metallic glass systems to synthesize

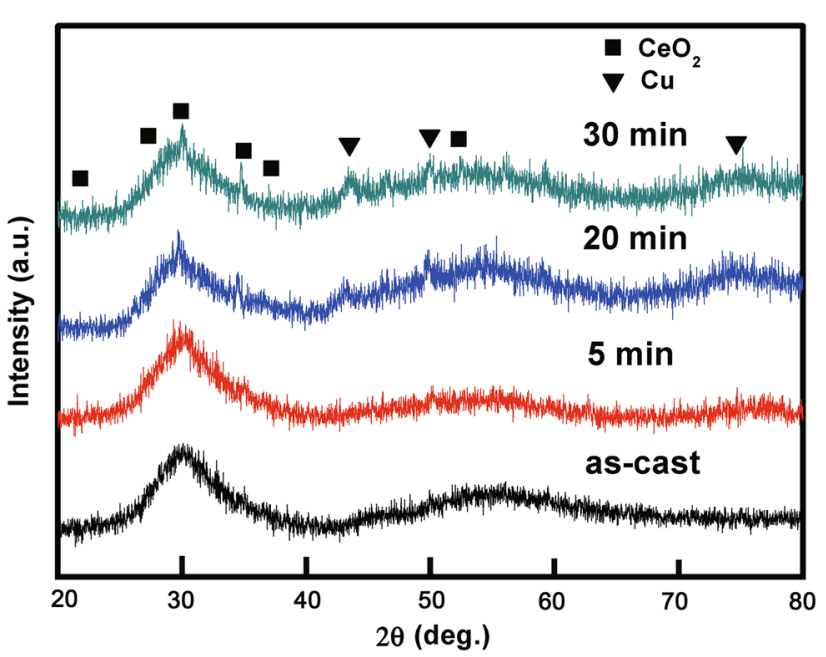

Fig. 1 XRD patterns of the as-cast $\left(\mathrm{La}_{0.5} \mathrm{Ce}_{0.5}\right)_{65} \mathrm{Al}_{10} \mathrm{Cu}_{25}$ bulk metallic glasses and the corresponding corroded samples in $0.1 \mathrm{~mol} / \mathrm{L} \mathrm{H}_{2} \mathrm{SO}_{4}$ aqueous solution at $298 \mathrm{~K}$ for 5,20 and $30 \mathrm{~min}$, respectively 

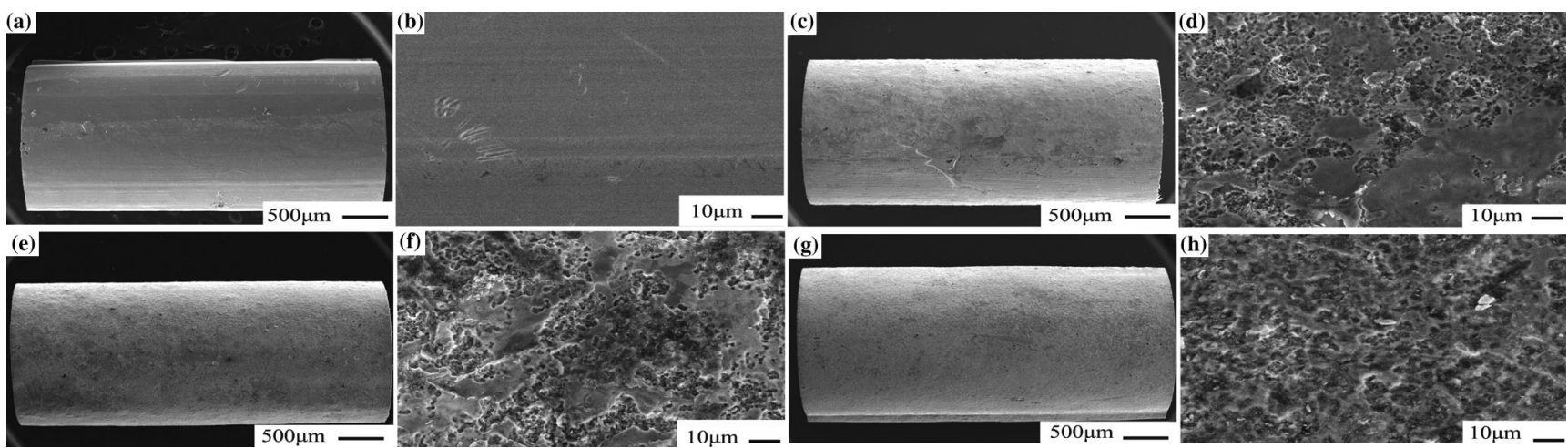

Fig. 2 SEM images of surface morphologies of $\mathbf{a}, \mathbf{b}$ the as-cast $\left(\mathrm{La}_{0.5} \mathrm{Ce}_{0.5}\right)_{65} \mathrm{Al}_{10} \mathrm{Cu}_{25}$ glassy rods and the corroded ones at $298 \mathrm{~K}$ in $0.1 \mathrm{~mol} / \mathrm{L}$ $\mathrm{H}_{2} \mathrm{SO}_{4}$ aqueous solution for different immersing time: c, d $5 \mathrm{~min}$; e, f $20 \mathrm{~min} ; \mathbf{g}, \mathbf{h} 30 \mathrm{~min}$

nanoporous metals [21-23]. The chemical reactions of the corrosion process mainly include three equations:

$2 \mathrm{La}+6 \mathrm{H}^{+} \rightarrow 2 \mathrm{La}^{3+}+3 \mathrm{H}_{2}$

$2 \mathrm{Ce}+6 \mathrm{H}^{+} \rightarrow 2 \mathrm{Ce}^{3+}+3 \mathrm{H}_{2}$;

$2 \mathrm{Al}+6 \mathrm{H}^{+} \rightarrow 2 \mathrm{Al}^{3+}+3 \mathrm{H}_{2}$.

Due to intensive affinity between rare earth and oxygen atoms, the rare earth oxide can be formed in the interface of corrosion reaction identified in the XRD patterns. The conclusion is also supported by the observation of the enrichment of $\mathrm{O}$ element in corrosion surface according to the EDX results (not shown here).

Figure 2 shows SEM images of the surface morphologies of the as-cast and corroded BMG rods of $\left(\mathrm{La}_{0.5-}\right.$ $\left.\mathrm{Ce}_{0.5}\right)_{65} \mathrm{Al}_{10} \mathrm{Cu}_{25}$. For the as-cast BMG sample, as shown in Fig. 2a, b, the surface is glabrous with a few scratches. General corrosion happens on the treated surface because of high electrochemical activity of lanthanide-based metallic glasses, similar to the dealloying processes in other metallic glass systems [22-25]. The corrosion region with obvious defects gradually enlarges with increasing immersing time from 5 to $30 \mathrm{~min}$, as shown in Fig. 2c-h. The density of corrosion defects increases with increasing immersing time. The distribution of the pit-like defects is irregular firstly for the corroded samples for $5 \mathrm{~min}$, while becomes more and more homogenous on the surface of the BMG rods with increasing immersing time. The homogeneity of the pits and corrosion region can be roughly adjusted by controlling the immersing time. With increasing immersing time, the corrosion interface proceeds evenly inwards the metallic matrix, leading to an increase in thickness of corrosion layer from $\sim 30 \mu \mathrm{m}$ for $5 \mathrm{~min}$ to $\sim 50 \mu \mathrm{m}$ for $30 \mathrm{~min}$. Because all of the samples will be treated using an ultrasonic device before the compressive tests, the actual thickness of the corroded layer increases from $\sim 6$ to $\sim 8 \mu \mathrm{m}$ for the samples with increasing immersing time from 5 to $30 \mathrm{~min}$.
Compressive stress-strain curves of the as-cast and corroded glassy rods of $\left(\mathrm{La}_{0.5} \mathrm{Ce}_{0.5}\right)_{65} \mathrm{Al}_{10} \mathrm{Cu}_{25}$ are shown in Fig. 3. The untreated BMG samples exhibit a brittle fracture behavior without yielding and plasticity. The compressive strength $\left(\sigma_{\mathrm{c}}\right)$ of the untreated ones is $(630 \pm 9) \mathrm{MPa}$. Yielding and plastic deformation behaviors appear for all of the samples after the surface modification. The yield strength $\left(\sigma_{\mathrm{y}}\right)$ for the corroded samples is similar to the value of $\sigma_{\mathrm{c}}$ for the untreated ones and changes indistinctively with increasing immersing time. The plasticity $\left(\varepsilon_{\mathrm{p}}\right)$ increases gradually from 0 for the untreated samples to $(0.30 \pm 0.05) \%$ for the corroded ones with immersing time of $30 \mathrm{~min}$. Therefore, the brittleness of the $\left(\mathrm{La}_{0.5} \mathrm{Ce}_{0.5}\right)_{65} \mathrm{Al}_{10} \mathrm{Cu}_{25} \mathrm{BMG}$ can be improved by the proper chemical surface treatment.

Figure 4 shows the SEM images of compressive fracture surfaces of the as-cast and corroded samples. For comparison, the selected typical surface regions for the four samples were presented by sequential SEM image

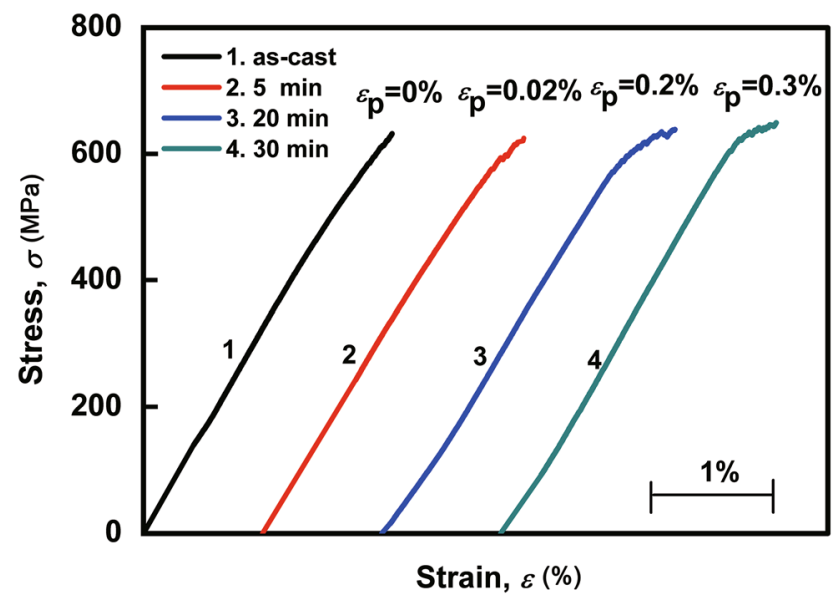

Fig. 3 Compressive stress-strain curves of the as-cast $\left(\mathrm{La}_{0.5} \mathrm{Ce}_{0.5}\right)_{65}$ $\mathrm{Al}_{10} \mathrm{Cu}_{25}$ glassy rods and the treated samples for different immersing time of 5,20 and $30 \mathrm{~min}$, respectively 

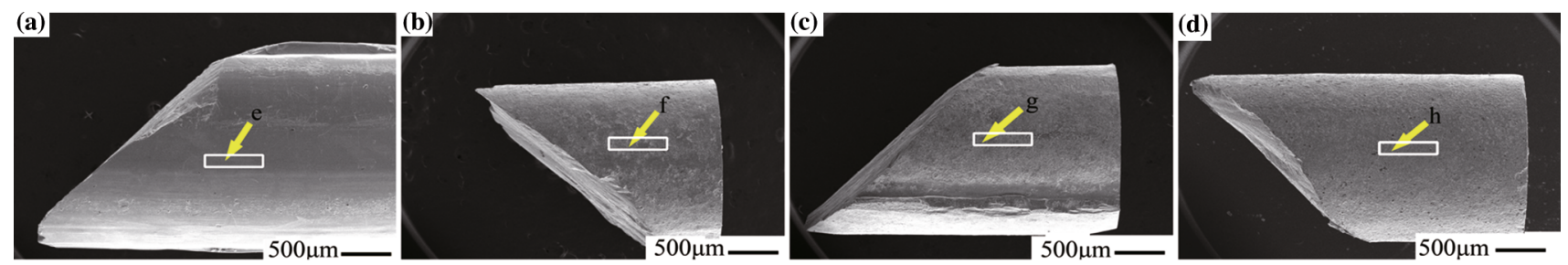

(e)

$10 \mu \mathrm{m}-$
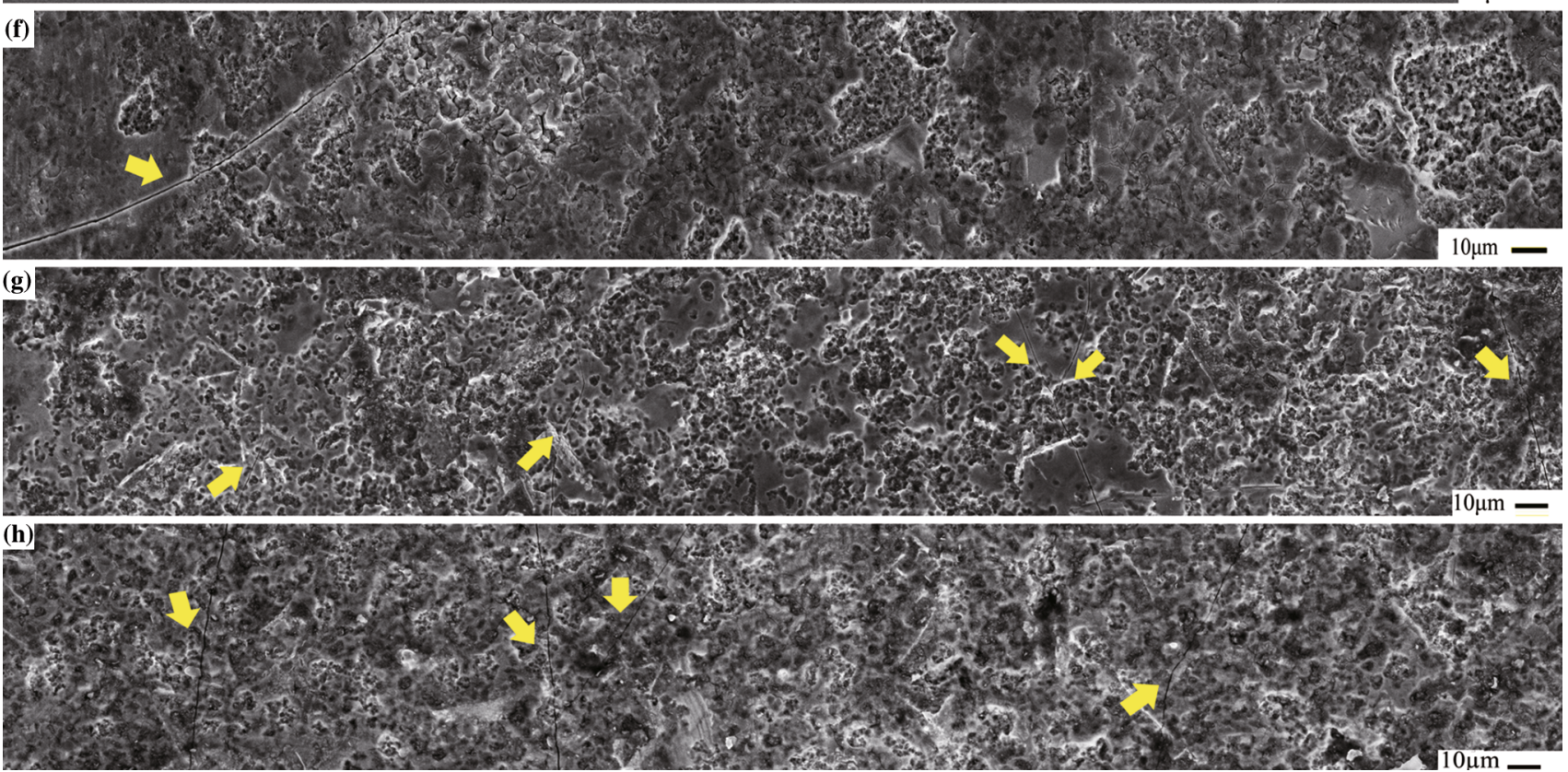

Fig. 4 SEM images of the failed $\left(\mathrm{La}_{0.5} \mathrm{Ce}_{0.5}\right)_{65} \mathrm{Al}_{10} \mathrm{Cu}_{25}$ glassy rods after compressive fracture for the different immersing time: a, e untreated; b, f $5 \mathrm{~min} ; \mathbf{c}, \mathbf{g} 20 \mathrm{~min} ; \mathbf{d}, \mathbf{h} 30 \mathrm{~min}$. The position of the typical selected surface morphologies for each sample, as shown in $\mathbf{e}-\mathbf{h}$, is highlighted by rectangle in $\mathbf{a}-\mathbf{d}$, respectively

stitching. As shown in Fig. 4a, e, no shear band can be observed on the smooth surface of the untreated BMG sample after catastrophic fracture. The failure of the corroded samples for different immersing time is still along the plane of the maximum shear stress and the fracture angle is about $45^{\circ}$ similar to the values of the as-cast sample. Only a few shear bands can be found on the surface of the failed sample corroded for 5 min (Fig. 4b, f), while abundant shear bands appear on the surface of the failed glass rods treated with longer immersing time of 20 and $30 \mathrm{~min}$ (Fig. 4c-d and $\mathrm{g}-\mathrm{h}$, respectively). Although no direct proof of the nucleation of shear bands initiated from corrosion defects was observed, the results of the significant improvement in plasticity for the treated samples suggested that the high density and homogenous distribution of corrosion defects could be beneficial for the nucleation of shear bands.

Figure 5 shows the immersing time dependence of the corrosion degree and the density of shear bands $\left(\rho_{\mathrm{sb}}\right)$ as well as the corresponding plasticity of the BMG samples. With increasing immersing time, the corrosion region with visible pit-like defects enlarges remarkably, and the corrosion degree increases from 0 for the as-cast samples to $75 \%$ for the corroded samples for $30 \mathrm{~min}$. Moreover, $\rho_{\mathrm{sb}}$ gradually increases from $0 \mu \mathrm{m}^{-1}$ for the as-cast samples to $0.00483 \mu^{-1}$ for the corroded samples for $30 \mathrm{~min}$. The $\rho_{\text {sb }}$ exhibits a roughly linear correlation with the plasticity of the samples. The results indicate that the significant increase in the number and length of shear bands (Figs. 4, $5)$ is responsible for the enhancement of plastic 


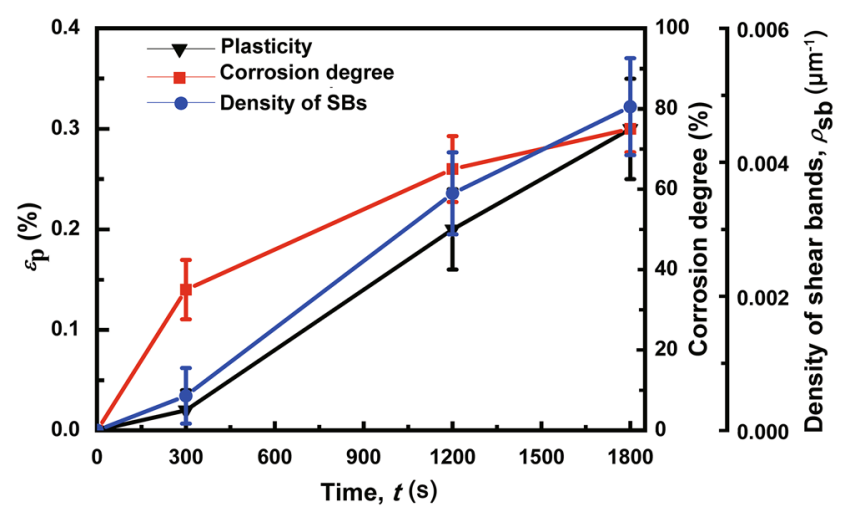

Fig. 5 Immersing time dependence of the corrosion degree, the density of shear bands and the plasticity for $\left(\mathrm{La}_{0.5} \mathrm{Ce}_{0.5}\right)_{65} \mathrm{Al}_{10} \mathrm{Cu}_{25}$ bulk metallic glasses

deformation. Surface heterogeneities caused by the highdensity corrosion defects with increasing corrosion degree can generate the increase in stress concentration on the sample surface, where the nucleation of shear bands can be easily initiated at a low stress level $[7,14]$. The promotion of the abundant nucleation of shear bands can directly result in the yield phenomenon and plastic deformation for the treated samples. So for the relatively short immersing time of $5 \mathrm{~min}$, the samples show obvious yielding but slight plasticity because the corrosion degree of the glassy rods is not sufficient to generate enough nucleated number of shear bands, while for longer immersing time of 20 or $30 \mathrm{~min}$, both yielding and plasticity are originated from the sufficient promotion of the formation of shear bands caused by high-density defects on the surface.

\section{Conclusion}

A chemical method of surface corrosion has been provided to enhance the plasticity of a brittle ( $\mathrm{La}, \mathrm{Ce}$ )-based BMG. The influences of immersing time on surface morphologies and mechanical properties of the $\left(\mathrm{La}_{0.5} \mathrm{Ce}_{0.5}\right)_{65} \mathrm{Al}_{10} \mathrm{Cu}_{25}$ BMG rods have been evaluated in $0.1 \mathrm{~mol} / \mathrm{L} \quad \mathrm{H}_{2} \mathrm{SO}_{4}$ aqueous solution under free corrosion conditions. With increasing immersing time from 5 to $30 \mathrm{~min}$, the corrosion region enlarges obviously with the high-density corrosion defects. The treated samples exhibit both yielding and plasticity (up to $0.3 \%$ ), while the as-cast sample shows the catastrophic failure without yielding. The increase in the corrosion degree can significantly promote the abundant nucleation of shear bands. Therefore, the surface corrosion method can provide a powerful way to improve the plasticity of BMGs.

Acknowledgments This work was financially supported by the National Natural Science Foundation of China (Nos. 51131002 and 51301196), the Fok Ying-Tong Education Foundation for Young Teachers in the Higher Education Institutions of China (No. 142008), the Fundamental Research Funds for the Central Universities (No. YWF-15-CLXY-002), and the Scientific Research Foundation for the Returned Overseas Chinese Scholars of State Education Ministry.

\section{References}

[1] A. Inoue, Acta Mater. 48, 279 (2000)

[2] M.F. Ashby, A.L. Greer, Scr. Mater. 54, 321 (2006)

[3] W.L. Johnson, JOM 54, 40 (2002)

[4] C.A. Schuh, T.C. Hufnagel, U. Ramamurty, Acta Mater. 55, 4067 (2007)

[5] J. Wang, R. Li, N. Hua, T. Zhang, J. Mater. Res. 26, 2072 (2011)

[6] O. Pelin, H. Aytekin, Acta Metall. Sin. (Engl. Lett.) 28, 733 (2015)

[7] A.L. Greer, Y.Q. Cheng, E. Ma, Mater. Sci. Eng. R 74, 71 (2013)

[8] L. Zhang, R. Li, T. Xu, H. Zhang, T. Zhang, Intermetallics 52, 92 (2014)

[9] J.W. Qiao, M.M. Meng, Z.H. Wang, C.J. Huang, R. Li, Y.S. Wang, H.J. Yang, Y. Zhang, L.F. Li, AIP Adv. 4, 107 (2014)

[10] T.G. Nieh, Y. Yang, J. Lu, C.T. Liu, Prog. Nat. Sci. 22, 355 (2012)

[11] Y. Zhang, W.H. Wang, A.L. Greer, Nat. Mater. 5, 857 (2006)

[12] J.P. Chu, J.E. Greene, J.S.C. Jang, J.C. Huang, Y. Shen, P.K. Liaw, Y. Yokoyama, A. Inoue, T.G. Nieh, Acta Mater. 60, 3226 (2012)

[13] W. Chen, K.C. Chan, P. Yu, G. Wang, Mater. Sci. Eng. A 528, $2988(2011)$

[14] S. Scudino, B. Jerliu, S. Pauly, K.B. Surreddi, U. Kuehn, J. Eckert, Scr. Mater. 65, 815 (2011)

[15] B. Sarac, J. Schroers, Nat. Commun. 4, 2158 (2013)

[16] B. Chen, Y. Li, M. Yi, R. Li, S. Pang, H. Wang, T. Zhang, Scr. Mater. 66, 1057 (2012)

[17] G. Wu, R. Li, Z. Liu, B. Chen, Y. Li, Y. Cai, T. Zhang, Intermetallics 24, 50 (2012)

[18] R. Li, F. Liu, S. Pang, C. Ma, T. Zhang, Mater. Trans., JIM 48, 1680 (2007)

[19] T. Zhang, R. Li, S. Pang, J. Alloy. Compd. 483, 60 (2009)

[20] R.T. DeHoff, in Q. Microscopy, ed. by F.N. Rhines, McGrawHill Series in Materials Science and Engineering (McGraw-Hill, New York, NY, 1968), p. 129

[21] Z. Deng, C. Zhang, L. Liu, Intermetallics 52, 9 (2014)

[22] X.K. Luo, R. Li, L. Huang, T. Zhang, Corros. Sci. 67, 100 (2013)

[23] X.K. Luo, R. Li, Z.Q. Liu, L. Huang, M.J. Shi, T. Xu, T. Zhang, Mater. Lett. 76, 96 (2012)

[24] Y. Jin, R. Li, T. Zhang, Intermetallics 67, 166 (2015)

[25] R. Li, X.J. Liu, H. Wang, Y. Wu, X.M. Chu, Z.P. Lu, Corros. Sci. 84, 159 (2014) 